\title{
Monitoring of endostatin, TNF- $\alpha$ VEGFs, MMP-9, and cathepsin-L during three months of diosmin treatment in patients with chronic venous disease (CVD)
}

\author{
Marcin Feldo', Magdalena Wójciak-Kosior², Ireneusz Sowa ${ }^{2}$, Janusz Kocki ${ }^{3}$, Jacek Bogucki ${ }^{3}$, \\ Tomasz Zubilewicz', Wacław Karakuła', Anna Bogucka-Kocka ${ }^{4}$ \\ 'Department of Vascular Surgery and Angiology, Medical University of Lublin, Poland \\ ${ }^{2}$ Department of Analytical Chemistry, Medical University of Lublin, Poland \\ ${ }^{3}$ Department of Clinical Genetics, Medical University of Lublin, Lublin, Poland, \\ ${ }^{4}$ Chair and Department of Biology and Genetics, Medical University of Lublin, Poland
}

\begin{abstract}
Introduction: Primary CVD as a result of increased venous hypertension caused mostly by reflux from valvular incompetence as an indication for venoactive drug treatment. The objective of the study was the association between three months of treatment with diosmin and changes to the angiogenic factors involved in the pathophysiology and clinical symptoms of CVD.

Material and methods: 4 I patients were included in the study. Plasma levels of tumour necrosis factor $\alpha$ (TNF- $\alpha$ ), vascular endothelial growth factor (VEGF-A and VEGF-C), matrix metalloproteinase 9 (MMP-9), Cathepsine-L and endostatin were measured using an ELISA assay at baseline and after three months of diosmin administration. Clinical evaluation was performed using duplex Doppler, the VAS scale, leg circumference measurement and $\mathrm{BMl}$ score.

Results: Three-month treatment with diosmin was associated with a statistically significant decrease in TNF- $\alpha$, VEGF-A, VEGF-C, MMP-9, Cathepsin-L and endostatin plasma levels with $p<0.01$ and $p<0.05$ respectively. The average ankle circumference decreased significantly from $30.45( \pm 2.05)$ to $29.0( \pm 1.43)(p<0.05)$. Conclusion: Diosmin influence on the inflammatory and proteolytic mechanisms involved in the pathology of CVD, could modify endostatin release and angiogenic processes.
\end{abstract}

Key words: CVD, endostatin, diosmin, pro-inflammatory factors, angiogenesis

Acta Angiol 2019; 25, I: 7-13

\section{Introduction}

Pharmacological treatment of chronic venous disease (CVD) includes venoactive drugs that influence venous tone or capillary permeability and reduce leukocyte infiltration. Diosmin is a flavonoid that improves lymphatic activity, microvascular permeability and microcirculatory flow by affecting the endothelium function and reducing oedema and inflammation [I].
Anti-inflammatory properties including inhibition of TNF- $\alpha$, leukotriens synthesis and leukocyte activation/ /degranulation may increase microcirculatory blood flow and reduce oedema [2]. Some studies show significant changes in MMP expression and activity in relation to CVD caused by a prolonged increase to venous wall tension [3]. Immunohistochemical analyses of varicose vein tissue showed prominent localisation of MMP-9 in the endothelial cells, intimal and adventitial layers of 
varicose veins and such localisation is consistent with the role of MMP - degradation of extracellular matrix (ECM) proteins, collagen and elastin [4, 5]. The imbalance in ECM protein degradation and increased plasma levels of MMPs correlated with d-dimers and elevated plasminogen activator inhibitor (PAI-I) suggesting a pro-thrombotic and pro-inflammatory state [6]. The prolonged pro-inflammatory state may result in changes to the endogenous angiogenic response through the release of pro-angiogenic (VEGF-A and VEGF-C) and anti-angiogenic agents i.e. endostatin as a cleavage fragment of collagen XVIII, a proteoglycan/ /collagen found in the vessel wall and basement membranes [7-9]. Endostatin, a proteolytic fragment of the $\mathrm{NCl}$ domain of collagen XVIII/proteoglycan, was identified as an endogenous angiogenesis inhibitor first isolated from the conditioned media of non-metastatic murine haemangioendothelioma cell lines EOMA [10]. As proteolytic activity is present in the CVD mechanism and endostatin is a collagen XVIII cleavage product it seemed to be justified to elucidate its role in the mechanisms involved in this pathology.

Following this premise, we hypothesized that circulating endostatin plays a role in CVD pathophysiology and its plasma level may respond to prolonged administration of diosmin.

\section{Material and methods}

\section{Patients}

Forty-one patients (20 men and 21 women, mean age $4 \mathrm{I}$ years) were enrolled in the study. Participants gave their informed consent before enrolment. Local ethics committee approval was obtained (KE 0254/34 I/20 I 5). Medical history was taken and clinical examination was performed for all patients. Clinically, and then echographically (Doppler ultrasound Toshiba Aplio, $5 \mathrm{MHz}$ linear probe) diagnosed chronic venous disease was evaluated [II]. ABI was assessed in each patient. Inclusion criteria were as follows: Bilateral greater saphenous vein (GSV) insufficiency detailed CEAP [12] classification stage C2, C3 and C4, and not using venoactive drugs 30 days before inclusion in the trial. None of the patients in the trial used graduated compression stockings. All participants stated that using them was unbearable. Patients received $2 \times 600 \mathrm{mg} /$ /day of diosmin (Phlebodia, Laboratoires Innothera, Arcueil, France). They were instructed not to change their daily habits.

\section{Exclusion criteria}

Exclusion factors were as follows: age $<18$ years, pregnancy, smoking, diabetes mellitus, chronic renal failure, liver and cardiac failure, diuretics medication, chronic infections, previous vein surgery, previous and present vein thrombosis, arterial and venous aneurysm, congenital vascular malformations, psoriasis, autoimmune disease and cancer.

\section{Laboratory procedures}

Blood samples were collected between 8:00 hr and 10:00 hr always after overnight fasting. EDTA tubes were used to collect the blood; plasma samples obtained were centrifuged at $1500 \times \mathrm{g}$ for $10 \mathrm{~min}$ and stored in a freezer $\left(-20^{\circ} \mathrm{C}\right)$ until use. Total TNF- $\alpha$, VEGF-C (Thermo Fisher, USA), VEGF-A (PromoCell $\mathrm{GmbH}$, Germany), MMP-9, Cathepsin-L and Endostatin (Elabscience, USA) levels were determined in duplicate by commercially available enzyme-linked immunosorbent assay (ELISA) and the mean value of both determinations was used. The procedures were performed strictly to manufacturer instructions.

\section{Leg circumferences, BMI and pain assessment}

Leg circumferences were taken $13 \mathrm{~cm}$ from the floor in a standing position [13]. The procedure was done separately by two independent observers in the same temperature conditions and at the same time of day - 10:00 am. The result presented was the mean of the two leg measurements. BMI was calculated as weight $/$ height ${ }^{2}\left(\mathrm{~kg} / \mathrm{m}^{2}\right)$. Pain level was assessed using the visual analogue scale (VAS) which went from 0 (no pain) to $10 \mathrm{~cm}$ (intolerable pain).

Each study participant was consulted every 30 days during the study period. Laboratory procedures, leg circumferences, pain and $\mathrm{BMI}$ were assessed twice at baseline (T0) and at day 90 (T3m).

\section{Statistical analysis}

Statistical analysis of the results (Statistica 10 software, StatSoft Polska) was carried out using descriptive statistics and the following parameters: group size $(\mathrm{N})$, arithmetic mean, median, minimum and maximum variables and standard deviation (SD). The study groups were compared using the Kruskal-Wallis multiple comparison test. Correlation analyses were performed using the Spearman's test.

\section{Results}

The clinical characteristics of the patients are summarised in Table I.

\section{Clinical symptoms}

The estimation of clinical symptoms allowed the division of the patients with $\mathrm{CVI}$ into particular classes: C2 - varicose vein; C3 - varicose vein and oedema; $\mathrm{C} 4$ - varicose vein, oedema and skin changes. Initially, 
Table. I. Patient demographics at baseline (T0)

\begin{tabular}{|l|c|}
\hline $\mathrm{N}$ & $4 \mathrm{I}$ \\
\hline Age & $39.73 \pm 8.25$ \\
\hline Male/ Female & $20 / 2 \mathrm{I}$ \\
\hline BMI & $25.95( \pm \mathrm{I} .62)$ \\
\hline CEAP C2 & 14 \\
\hline C3 & 16 \\
\hline C4 & $1 \mathrm{I}$ \\
\hline GSV reflux & $4 \mathrm{I}(100 \%)$ \\
\hline ABI & $\mathrm{I} .1 \pm(0.1 \mathrm{I})$ \\
\hline Dyslipidaemia & $\mathrm{I}(2.43 \%)$ \\
\hline Hypertension & $2(4.87 \%)$ \\
\hline Statins & $\mathrm{I}(2.43 \%)$ \\
\hline Betablockers & $2(4.87 \%)$ \\
\hline
\end{tabular}

ultrasound examination (echo-Doppler assay) was used to assess blood flow changes in superficial and deep veins during the compression manoeuvre in standing position [I I]. Bilateral GSV insufficiency with reflux longer than I sec. was assessed in $4 \mathrm{I}$ (I00\%) patients.

After three months of treatment with diosmin, no changes were noted in the echo-Doppler examinations, there were no episodes of thrombophlebitis or thromboembolism. B-mode echography showed a decrease of subcutaneous lymph in seven $\mathrm{C} 3$ and three $\mathrm{C} 4$ patients. There was a statistically significant decrease in the average leg circumference of patients $(p<0.05)$ from $30.45( \pm 2.05)$ to $29.0( \pm 1.43)$ so the reduction in leg circumference was $4.6 \%$ in comparison T0 vs. T3m.

Pain, assessed on the VAS scale, was absent in 12 (29.2\%) participants of our study. The other patients reported minor pain ranging from I to 3 on the VAS scale and after three months of diosmin administration, 19 patients reported less severe pain. The differences in reported pain levels at T0 vs T3m among the $\mathrm{C} 2, \mathrm{C} 3$ and $\mathrm{C} 4$ groups were statistically insignificant.

\section{Basic blood parameters}

Blood parameters were monitored at $\mathrm{T} 0$ and after three months of diosmin treatment to assess possible changes or abnormalities. The results are summarized in Table 2. The values obtained for each patient were within the acceptable range and no statistically significant changes $(p<0.05)$ in the level of the investigated factors were observed in patients after treatment with diosmin.

\section{Monitoring levels of TNF- $\alpha$, VEGF-A and VEGF-C}

There was a statistically significant decrease of average plasma levels of TNF- $\alpha$, VEGF-C, and VEGF-A after
Table 2. The average value $( \pm S D)$ of selected physiological parameters in patients before (T0) and after three months of treatment $(\mathrm{T} 3 \mathrm{~m})$ with diosmin

\begin{tabular}{|l|c|c|}
\hline Parameter & \multicolumn{1}{c}{ T0 } & T3m \\
\hline Leukocytes $[\mathrm{K} / \mu \mathrm{L}]$ & $4.78( \pm 0.5)$ & $5.67( \pm 0.6)$ \\
\hline $\begin{array}{l}\text { Total cholesterol } \\
{[\mathrm{mmol} / \mathrm{l}]}\end{array}$ & $4.1( \pm \mathrm{I} . \mathrm{I})$ & $4.4( \pm 0.6)$. \\
\hline Triglycerides $[\mathrm{mmol} /]$ & $\mathrm{I} .6( \pm 0.4)$ & $1.7( \pm 0.3)$ \\
\hline CRP $[\mathrm{mg} / \mathrm{dl}]$ & $3.9( \pm 0,9 \mathrm{I})$ & $3.4( \pm 0.88)$ \\
\hline $\begin{array}{l}\text { Complement C3 } \\
{[\mathrm{mmol} / \mathrm{l}]}\end{array}$ & $\mathrm{I} .56( \pm 0.4)$ & $\mathrm{I} .63( \pm 0.48)$ \\
\hline $\begin{array}{l}\text { Complement C4 } \\
{[\mathrm{mmol} / \mathrm{l}]}\end{array}$ & $0.53( \pm 0.63)$ & $0.49( \pm 0.15)$ \\
\hline Fibrinogen $[\mathrm{mg} / \mathrm{dl}]$ & $318.4( \pm 82.9)$ & $331( \pm 90.8)$ \\
\hline D-dimer $[\mu \mathrm{g} / \mathrm{l}]$ & $4 \mathrm{I} .9( \pm \mathrm{I} 28.8)$ & $378.5( \pm \mathrm{I00.5})$ \\
\hline INR & $0.93( \pm 0.12)$ & $0.97( \pm 0.15)$ \\
\hline Creatinine $[\mu \mathrm{mol} / \mathrm{l}]$ & $82( \pm 2.7)$ & $89( \pm 3.2)$ \\
\hline Albumin $[\mathrm{g} / \mathrm{dl}]$ & $4.65( \pm \mathrm{I} .76)$ & $4.87( \pm 0.8 \mathrm{I})$ \\
\hline Sodium $[\mathrm{mmol} / \mathrm{l}]$ & $140.27( \pm \mathrm{I} .24)$ & $\mathrm{I} 38.10( \pm \mathrm{I} .38)$ \\
\hline BMI & $25.95( \pm \mathrm{I} .62)$ & $25.85( \pm \mathrm{I} .72)$ \\
\hline
\end{tabular}

Table 3. The mean level ( \pm SD) of TNF- $\alpha$, VEGF-A and VEGF-C in plasma before and after three months of treatment with diosmin

\begin{tabular}{|c|c|c|c|}
\hline & $\begin{array}{l}\text { TNF- } \alpha \\
(\mathrm{pg} / \mathrm{ml})\end{array}$ & $\begin{array}{l}\text { VEGF-A } \\
\text { (pg/ml) }\end{array}$ & $\begin{array}{l}\text { VEGF-C } \\
(\mathrm{pg} / \mathrm{ml})\end{array}$ \\
\hline TO & $1087.79( \pm 384.9)$ & $88.3( \pm 103.4)$ & $527.18( \pm 143.4)$ \\
\hline T3m & $408.0( \pm 15 \mid .8)^{* * *}$ & $48.06( \pm 19.2)^{*}$ & $370.1( \pm 66.8)^{*}$ \\
\hline
\end{tabular}

Note: ${ }^{*} \mathrm{p}<0.05,{ }^{* *} \mathrm{p}<0.001$

diosmin therapy of $p<0.01$ and $p<0.05$, respectively. The results are listed in Table 3 and shown on Figure I.

\section{Monitoring levels of MMP-9, Cathepsin-L and Endostatin}

There was a statistically significant decrease in the average plasma levels of MMP-9 and cathepsin- $L$ after three months of diosmin treatment of $p<0.05$ and a statistically significant $(p<0.05)$ decrease of plasma endostatin at T3m in comparison to baseline was found as presented in Table 4 and Figure 2.

\section{Analysis of data from C2, C3 and C4 CEAP}

Analysing the data from individual classifications of CVD patients, no statistically significant differences in levels of TNF- $\alpha$, VFGF-A, VEGF-C, MMP-9, cathepsin-L and endostatin among $\mathrm{C} 2, \mathrm{C} 3$ and $\mathrm{C} 4$ patients were noted before and after diosmin treatment. 
Table 4. The mean content ( \pm SD) of MMP-9, Cathepsin-L and endostatin in plasma before and after three months of treatment with diosmin

\begin{tabular}{|c|c|c|c|}
\hline & $\begin{array}{l}\text { MMP-9 } \\
(\mathrm{ng} / \mathrm{ml})\end{array}$ & $\begin{array}{l}\text { Cathepsin-L } \\
\text { (ng/ml) }\end{array}$ & $\begin{array}{l}\text { Endostatin } \\
(\mathrm{pg} / \mathrm{ml})\end{array}$ \\
\hline TO & $77.83( \pm$ I7.7) & $3.44( \pm 0.8 \mathrm{I})$ & $102.08( \pm 24.4)$ \\
\hline T3m & $67.93( \pm 15.1)^{*}$ & $2.66( \pm 1.0)^{*}$ & $84.4 \pm(14.0)^{*}$ \\
\hline
\end{tabular}

Note: ${ }^{*} p<0.05$

\section{Correlations analyses}

Correlation analyses performed using the Spearman's test $(p<0.05, s<0.05)$ revealed statistically significant positive correlation between:
- endostatin T3m and MMP-9 at T3m $(r=0.33)$,

- MMP-9 T3m and cathepsin-L at T3m ( $r=0.44)$.

Moreover, a negative correlation between endostatin TO and VEGF-C TO ( $r=-0.38)$ was noted (Fig. 3). There was a notable opposite correlation between endostatin and VEGF-C after three months of treatment with diosmin but without significance $(r=0.03)$.

\section{Discussion}

In the present study, a significant association was found between plasma levels of endostatin, a fragment of vascular basement membrane collagen, and the inflammatory state corrected by prolonged diosmin administration. In our study, the highest levels of fac-
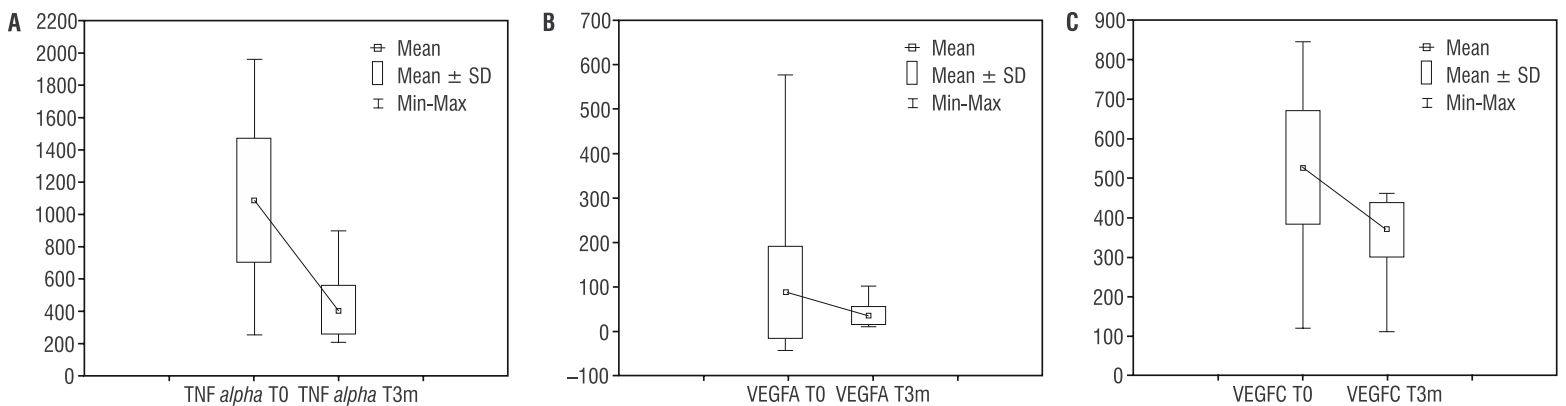

Figure I. Plasma levels of TNF- $\alpha$, VEGF-A, VEGF-C, before (T0) and after three months (T3m) of diosmin treatment
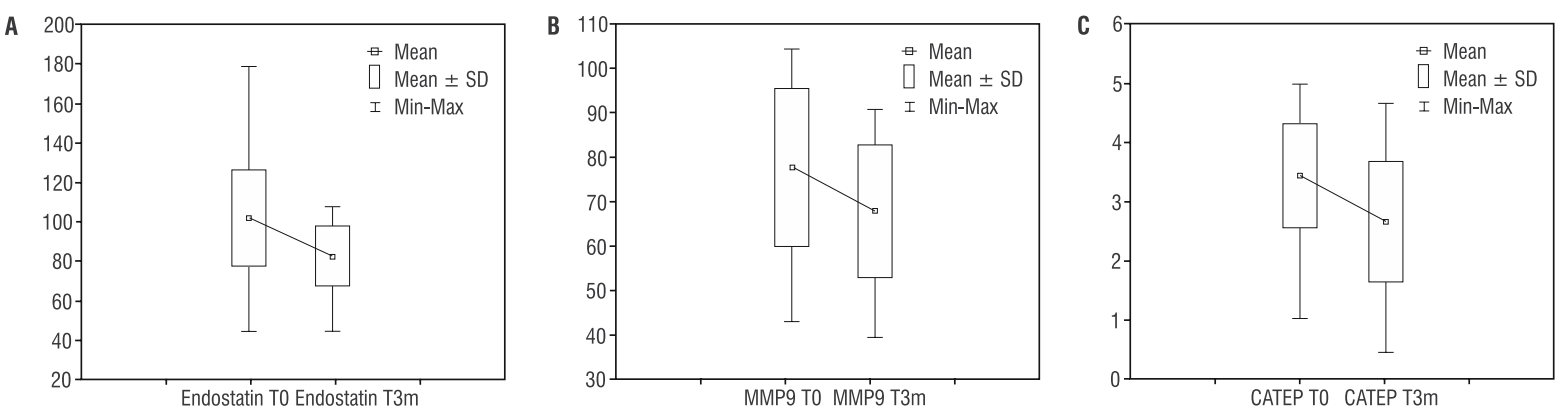

Figure 2. Plasma levels of endostatin (A), MMP-9 (B), and cathepsin-L (C) at baseline (T0) and after three months (T3m) of diosmin treatment
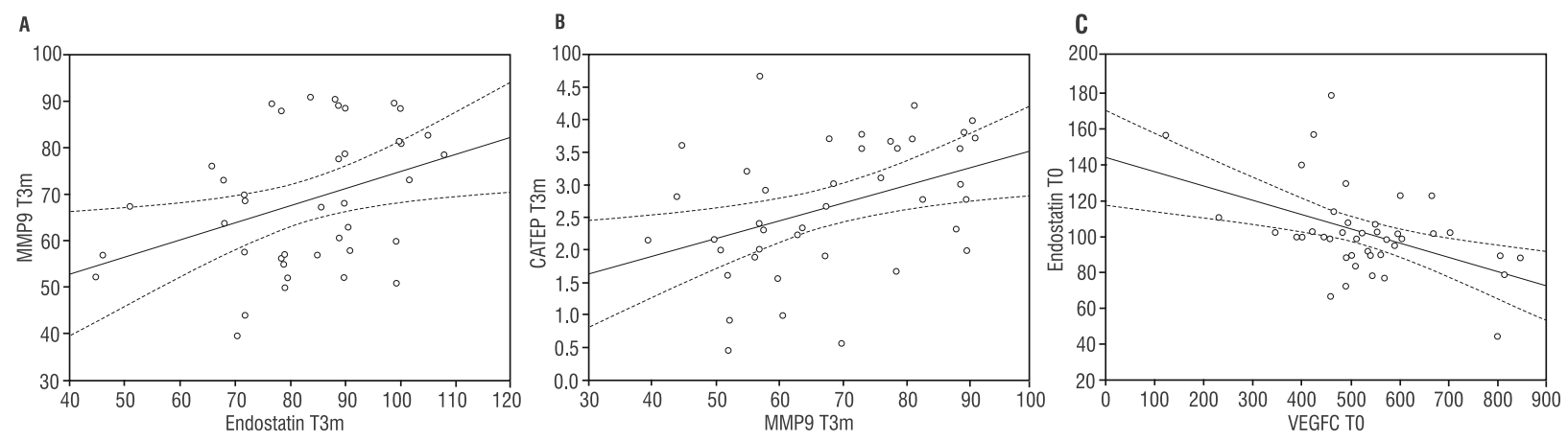

Figure 3. A. Positive correlation between endostatin and MMP-9 plasma levels at T3m. B. Positive correlation between MMP-9 and cathepsin-L plasma level at T3m. C. Negative correlation between VEGF-C and endostatin plasma levels at T0 
tors regulating angiogenesis - endostatin and VEGFs peptides - were seen in the plasma of patients before diosmin treatment.

The imbalance of vasoactive substances may contribute to relaxation and remodelling of varicose veins. Due to venous dilatation and valvular incompetence blood flow in varicose veins is disrupted, resulting in the blood stasis and reflux observed in all patients in our study. After three months of diosmin treatment, a significant reduction of leg circumferences was observed as a result of oedema regression.

However, the decrease in pain reported after three months of diosmin treatment was not statistically significant. Currently available venoactive drugs can attenuate various features of the inflammatory cascade, particularly the leukocyte-endothelium interactions leading to proteases release/activation and microvascular hyperpermeability causing leg oedema associated with clinical symptoms in patients affected by CVD [7].

Besides vascular inflammation and remodelling, the endothelium can regulate venous tone and microvascular permeability through the release of inflammatory mediators. In our study, the increased plasma level of TNF- , VEGF-A and VEGF-C at baseline correlates with the leg oedema objectively defined by leg circumference. As proangiogenic substances, VEGFs have a stimulatory effect on endothelial cells, inducing their proliferation and promoting base membrane/endothelium complex permeability resulting in increased oedema. Angiogenesis is initiated by cytokines such as fibroblast growth factor (FGF) and VEGF but in later stages, this process becomes dependent on platelet-derived growth factors (PDGF) and transforming growth factor-I (TGF-I) [I0, 14]. Inducers of angiogenesis bind to the cell surface of heparan sulphate proteoglycans. VEGF requires proteoglycans as cofactors in order to induce angiogenic signalling. Collagen XVIII is a core protein of heparan sulphate proteoglycan in vascular and epithelial basement membranes so in this context the physiological role of collagen $\mathrm{XVIII}$ in relation to endothelial cells may be a positive cofactor for angiogenesis [15]. On the other hand, during angiogenesis, endothelial cells and monocytes release proteolytic enzymes, MMPs and cathepsin- $L$ which cleave peptide bonds within the $\mathrm{NCI}$ domain of collagen XVIII and then endostatin is released in order to become a local angiogenesis inhibitor. The collagen/endostatin system may have been considered a sensor of proteolytic activities related to angiogenesis and serve as a negative control through the release of anti-angiogenic fragments $[10,16]$. In our study, the decrease of endostatin levels correlated positively with MMP-9 and cathepsin-L plasma levels at the end of the study (T3m) which may confirm diminished proteolysis due to diosmin activity. This kind of activity may also modify the abovementioned interactions between VEGF and vascular basement membrane proteoglycans.

The association between plasma proteolytic activity and endostatin levels confirmed that venous wall remodelling plays an active role in the mechanisms involved in CVD pathophysiology. ECM degradation is likely to contribute to the weakening and dilatation of veins. Disruption of the elastic fibres including fragmentation of elastic laminas and collagen fibres was observed in varicose veins and the total elastin content in varicose vein wall is decreased in comparison with non-varicose veins [17]. Loss of elastin and type III collagen correlates negatively with vein diameter measured by ultrasonography at rest and during the Valsalva manoeuvre and this alteration in the balance of elastin and collagen content may contribute to varicose vein wall weakening $[17,18]$.

ECM is a dynamic structure that maintains the integrity of the vein through interaction with cellular and extra-cellular components: the endothelium, the basic membrane, proteins, smooth muscle cells and fibroblasts. The development of CVD is characterised by inflammation, ECM degradation, proteolytic activity and oedema. Several different types of proteolytic enzymes such as cathepsins (-L, $-K)$ and matrix metalloproteinases (MMP-9 and -2 ) are involved in venous wall remodelling processes but in collagen XVIII, proteolysis MMP-9 and cathepsin-L activity were described [4, 19].

As mentioned, in our study the higher levels of MMP-9 were noted at baseline and decreased after three months of diosmin treatment. The nature of this mechanism is unknown because the regulation of MMP is complex and occurs at different levels, including gene transcription, protein translation, pro-MMP activation and endogenous inhibition by plasma proteins such as tissue inhibitors of metalloproteinase (TIMPs) and -2-macroglobulin [20]. Circulating concentration of endostatin has been reported to rise in other diseases including inflammatory bowel disease and preeclampsia.

To the authors' knowledge, there is currently no association reported between plasma levels of endostatin and CVD pathophysiology in the literature. Elevated levels of type XVIII collagen/endostatin have been associated with ischemic heart disease and stroke and have been linked to obesity and diabetes [8, I4]. In a study by Mitsuma et al. [16] the level of serum endostatin was inversely related to the extent of coronary collaterals suggesting that endostatin may play a role in collaterals formation. In contrast, Iribarren et al. [2I] observed an elevated risk of myocardial infarction in patients with lower serum endostatin levels. In the study by Holsti et al. [22], a significant association was found between 
the plasma levels of fragments from type IV collagen, collagen XVIII/endostatin as vascular membrane proteins and infrarenal aorta diameter. The highest level of these vascular basement membrane fragments was seen in the group with an established abdominal aortic aneurysm. The levels of type IV and XVIII collagen/endostatin were significantly and independently associated with the aortic diameter group, after adjusting for risk factors - diabetes, hypertension and current smokers. As patients with diabetes and current smokers were not included in our study, we could not draw conclusions in that regard.

There is no current consensus on the role of circulating endostatin in vascular disease but some authors support the hypothesis that circulating endostatin may be a marker of impaired collateral formation and reduced angiogenesis. Some studies showed significantly higher levels of serum VEGF and endostatin in patients at more advanced stages of heart failure. The concentration of pro-inflammatory and angiogenic factors i.e. interleukin-6, fibroblast growth factor (FGF) and endostatin were significantly associated with the presence of coronary collaterals and their formation is associated with the activation of pro-inflammatory factors and endostatin [15, 22, 23]. In order to elucidate the role of endostatin in CVD pathophysiology, an investigation into areas of other angiogenic cytokines such as IL-6, RANTES or Angiopietin-I, appears necessary.

The study was limited by the small number of patients included but in fact the study cohort recruited was highly homogenous and all patients remain in observation until the end of the study. Our findings need to be confirmed in a larger study group and compared with more severe diseases (C5 and C6 CEAP) and healthy controls.

\section{Conclusions}

To conclude, diosmin may influence the proteolysis mechanisms involved in ECM and basic membrane degradation which was expressed in our study by the decreased MMP-9, cathepsin- $L$ and endostatin plasma levels. Elevated plasma levels of endostatin can be perceived as a marker of venous basement membrane degeneration and vein wall remodelling, which was previously demonstrated in the different abovementioned vascular diseases.

\section{Conflict of interest}

None.

\section{References}

I. Cesarone MR, Belcaro G, Pellegrini L, et al. Venoruton vs Daflon: evaluation of effects on quality of life in chronic ve- nous insufficiency. Angiology. 2006; 57(2): 131-138, doi: 10.1 I77/00033 | 97060570020 I, indexed in Pubmed: 165 |85 I9.

2. Raffetto JD, Eberhardt RT, Dean SM, et al. Pharmacologic treatment to improve venous leg ulcer healing. J Vasc Surg Venous Lymphat Disord. 2016; 4(3): 37I-374, doi: 10.1016/j. jvsv.2015.10.002, indexed in Pubmed: 27318060.

3. Kucukguven A, Khalil RA. Matrix metalloproteinases as potential targets in the venous dilation associated with varicose veins. Curr Drug Targets. 2013; 14(3): 287-324, indexed in Pubmed: 23316963.

4. Naik B, Kumar M, Khanna AK, et al. Clinico-histopathological study of varicose vein and role of matrix metalloproteinases-I, matrix metalloproteinases-9 and tissue inhibitor of matrix metalloproteinase-I in varicose vein formation. Indian J Pathol Microbiol. 2016; 59(I): 25-30, doi: 10.4103/0377-4929. 178217 , indexed in Pubmed: 26960630.

5. Sansilvestri-Morel P, Fioretti F, Rupin A, et al. Comparison of extracellular matrix in skin and saphenous veins from patients with varicose veins: does the skin reflect venous matrix changes? Clin Sci (Lond). 2007; I I2(4): 229-239, doi: 10.1042/CS20060।70, indexed in Pubmed: 1702054l.

6. Dzieciuchowicz L, Espinosa G, Páramo JA. Increased Levels of Metalloproteinase 10 and Hemostatic Markers in Patients With Noncomplicated Primary Varicose Veins. Clin Appl Thromb Hemost. 20I5; 2I(7): 684-687, doi: I0.1 I77/I0760296/35 I7/67, indexed in Pubmed: 24413984.

7. Bergan J, Pascarella L, Schmid-Schönbein G. Pathogenesis of primary chronic venous disease: Insights from animal models of venous hypertension. Journal of Vascular Surgery. 2008; 47(1): 183-192, doi: 10.1016/j.jvs.2007.09.028.

8. Golledge J, Clancy P, Hankey GJ, et al. Serum endostatin concentrations are higher in men with symptoms of intermittent claudication. Dis Markers. 2014; 2014: 298239, doi: 10.1 I55/2014/298239, indexed in Pubmed: 24600079.

9. Boisseau MR. Leukocyte involvement in the signs and symptoms of chronic venous disease. Perspectives for therapy. Clin Hemorheol Microcirc. 2007; 37(3): 277-290, indexed in Pubmed: 17726258.

10. Zatterstorm UK, Felbor U, Fukai N, et al. Collagen XVIII/Endostatin structure and functional role in angiogenesis. Cell Structure and Function. 2000; 25: 97-101.

II. Coleridge-Smith P, Labropoulos N, Partsch H, et al. UIP. Duplex ultrasound investigation of the veins in chronic venous disease of the lower limbs--UIP consensus document. Part I. Basic principles. Eur J Vasc Endovasc Surg. 2006; 31 (I): 83-92, doi: 10.1016/j.ejvs.2005.07.019, indexed in Pubmed: 16226898.

12. Eklöf Bo, Rutherford RB, Bergan JJ, et al. American Venous Forum International Ad Hoc Committee for Revision of the CEAP Classification. Revision of the CEAP classification for chronic venous disorders: consensus statement. J Vasc Surg. 2004; 40(6): 1248-1252, doi: 10.1016/j.jvs.2004.09.027, indexed in Pubmed: 15622385 .

13. Bérard A, Kurz X, Zuccarelli F, et al. VEINES Study Group. Venous Insufficiency Epidemiologic and Economic Study. Validity of the Leg-O-Meter, an instrument to measure leg circumference. Angiology. 2002; 53(I): 2I-28, doi: I0.1 I 77/00033 | 970205300 |04, indexed in Pubmed: I | 863306.

14. Arenillas JF, Alvarez-Sabín J, Montaner J, et al. Angiogenesis in symptomatic intracranial atherosclerosis: predominance of 
the inhibitor endostatin is related to a greater extent and risk of recurrence. Stroke. 2005; 36(I): 92-97, doi: 10.1161/01. STR.0000 I496 I7.65372.5d, indexed in Pubmed: 15550686.

15. Olsen BR. Life without perlecan has its problems. J Cell Biol. 1999; 147(5): 909-9|2, indexed in Pubmed: 105797।I.

16. Mitsuma W, Kodama M, Hanawa $\mathrm{H}$, et al. Serum endostatin in the coronary circulation of patients with coronary heart disease and its relation to coronary collateral formation. Am J Cardiol. 2007; 99(4): 494-498, doi: 10.1016/j.amjcard.2006.09.095, indexed in Pubmed: 17293192.

17. Wali MA, Dewan M, Eid RA. Histopathological changes in the wall of varicose veins. Int Angiol. 2003; 22(2): I88-193, indexed in Pubmed: 12865886.

18. Jeanneret C, Baldi T, Hailemariam S, et al. Selective loss of extracellular matrix proteins is linked to biophysical properties of varicose veins assessed by ultrasonography. Br J Surg. 2007; 94(4): 449-456, doi: 10. 1002/bjs.5630, indexed in Pubmed: 17262753.

19. Felbor U, Dreier L, Bryant RA, et al. Secreted cathepsin L generates endostatin from collagen XVIII. EMBO J. 2000; 19(6): I I87-I I94, doi: 10.1093/emboj/19.6.1 187, indexed in Pubmed: 10716919.
20. Lane T, Bootun R, Dharmarajah B, et al. Pathogenesis of primary varicose veins. Br J Surg. 2009; 96(II): I23।-1242, doi: 10.1002/bjs.6798, indexed in Pubmed: 1984786I.

2I. Iribarren C, Herrinton LJ, Darbinian JA, et al. Does the association between serum endostatin, an endogenous anti-angiogenic protein, and acute myocardial infarction differ by race? Vasc Med. 2006; II(I): 13-20, doi: 10.1191/1358863×06vm654oa, indexed in Pubmed: 16669408.

22. Holsti M, Wanhainen A, Lundin C, et al. Circulating Vascular Basement Membrane Fragments are Associated with the Diameter of the Abdominal Aorta and Their Expression Pattern is Altered in AAA Tissue. Eur J Vasc Endovasc Surg. 2018; 56(I): I 10-I 18, doi: 10.1016/j.ejvs.2018.03.002, indexed in Pubmed: 29656960.

23. Kobusiak-Prokopowicz M, Jołda-Mydłowska B, Grzebieniak T, et al. Expression of Proinflammatory Factors, Proangiogenic Factors and Endostatin in Patients with Heart Failure and Different Grades of Collateral Circulation Development. Adv Clin Exp Med. 2015; 24(6): 987-994, doi: 10.17219/acem/338।I, indexed in Pubmed: 26771970. 